\title{
Insulin/insulin-like growth factors in cancer: new roles for the aryl hydrocarbon receptor, tumor resistance mechanisms, and new blocking strategies
}

\section{Travis B. Salisbury* and Justin K. Tomblin}

Department of Pharmacology, Physiology and Toxicology, Joan C. Edwards School of Medicine, Marshall University, Huntington, WV, USA

\author{
Edited by: \\ Antonino Belfiore, University Magna \\ Graecia of Catanzaro, Italy \\ Reviewed by: \\ Andrea Morrione, Thomas Jefferson \\ University, USA \\ Elisa Wirthgen, Ligandis GbR, \\ Germany \\ ${ }^{*}$ Correspondence: \\ Travis B. Salisbury, Department of \\ Pharmacology, Physiology and \\ Toxicology, Joan C. Edwards School of \\ Medicine, Marshall University, 1 John \\ Marshall Drive, Huntington, WV \\ 25755, USA \\ e-mail: salisburyt@marshall.edu
}

The insulin-like growth factor 1 receptor (IGF1R) and the insulin receptor (IR) are receptor tyrosine kinases that are expressed in cancer cells. The results of different studies indicate that tumor proliferation and survival is dependent on the IGF1R and IR, and that their inhibition leads to reductions in proliferation and increases in cell death. Molecular targeting therapies that have been used in solid tumors include anti-IGF1R antibodies, anti-IGF1/IGF2 antibodies, and small molecule inhibitors that suppress IGF1R and IR kinase activity. New advances in the molecular basis of anti-IGF1R blocking antibodies reveal they are biased agonists and promote the binding of IGF1 to integrin $\beta 3$ receptors in some cancer cells. Our recent reports indicate that pharmacological aryl hydrocarbon receptor (AHR) ligands inhibit breast cancer cell responses to IGFs, suggesting that targeting AHR may have benefit in cancers whose proliferation and survival are dependent on insulin/IGF signaling. Novel aspects of IGF1R/IR in cancer, such as biased agonism, integrin $\beta 3$ signaling, AHR, and new therapeutic targeting strategies will be discussed.

\section{Keywords: IGF1R, IGF1, insulin, AHR, insulin receptor-A subtype, biased-agonism, MED-573, OSI-906}

\section{A SHORT HISTORY OF INSULIN/IGFS IN CANCER IGF1R}

The early evidence linking the IGF1R to cancer was the finding that the transformation of mouse embryo fibroblasts (MEFs) by many, but not all, tested oncogenes requires an intact Igflr gene. For instance, the SV40 large T antigen, H-Ras, EWS/FLI-1, and c$S r c$ transform wild type, but not Igfir null, MEFs (1-4). $G_{\alpha 13}$ and $v$-Src induces the transformation of wild type and IgfIr null MEFs $(4,5)$. Transgenic overexpression of oncogenic Kras in the murine mammary gland induces the formation of mammary tumors that overexpress Igfir (6). Such tumors resemble human basal-like breast tumors that are resistant to therapy (6). The growth of Kras expressing murine mammary tumors is delayed upon deletion of the Igflr gene from mammary tumors (6). Treating mice with the IGF1R inhibitor picropodophyllin (PPP) suppressed the growth of Kras expressing mammary tumors compared with vehicle (6). PPP also inhibited the growth of MDA-MB-231 breast cancer xenografts in mice (6). Collectively, these reports provided in vitro and in vivo evidence that the IGF1R promotes transformation and the progression of breast cancer.

\section{IGF1}

Liver specific Igf1 knockout mice have lower levels of circulating IGF1 (by $~ 75 \%$ ) than wild type mice $(7,8)$. Lowering the levels of circulating IGF1 in mice has been shown to inhibit the growth of colon cancer xenografts and there is reduced incidence of metastatic spread to the liver (7). Additionally, exogenous IGF1 increases the growth and metastasis of colon cancer in mice (7). Similar results were observed in murine models of breast cancer. Specifically, breast tumors grow slower in IGF1 deficient mice than wild type mice (9). On the other hand, transgenic overexpression of the human IGF1 gene in epithelial cells of the mouse prostate induces the formation of spontaneous prostate cancer (10). In humans, acromegaly is associated with higher incidence rates of colorectal cancer (11). In contrast, Laron-type dwarfism is associated with low IGF1 levels and reduced cancer risk (12). Thus, high levels of IGF1 are associated with increased incidence of cancer progression, while lower levels of IGF1 are associated with decreased incidence of cancer progression in mice and humans.

Canonical signaling responses to insulin/IGFs have been reviewed (13-16). Insulin/IGFs upon activation of their cognate receptors induce PI3K and MAPK signaling. Increases in PI3K and MAPK signaling in cancer cells induce proliferation and resistance to cell death $(17,18)$. In addition to the canonical insulin/IGF pathways, recent work indicates that insulin receptor substrate 1 (IRS-1) and the IGF1R translocate from the cell membrane into the nucleus in response to IGF1 $(19,20)$. In the nucleus, IRS1 binds to the promoters of CCND1 and $c M Y C$ (21). In doing so, IRS-1 increases the expression of CCND1 and $c M Y C$ (21). These findings provided a mechanism by which IGF1 through IRS-1 increases proliferation because CCND1 and $c M Y C$ induce cell cycle advance (21). IRS- 1 also binds to the promoter of ribosomal DNA (21). The binding of IRS-1 to the ribosomal DNA promoter promotes ribosomal RNA synthesis, which is required for increases in cell size (22). Ligand-induced translocation of the IGF1R into nucleus requires the IGF1R to undergo SUMOylation at specific lysine residues (Lys ${ }^{1025}$, Lys ${ }^{110}$, and Lys ${ }^{1120}$ in the $\beta$ subunit) (23). Upon entering the nucleus, SUMOylated IGF1R binds to lymphoid enhancer-binding factor 1 ( $L E F 1)$ on Wnt target gene 
promoters like CCND1 and AXIN (24). By this mechanism, the IGF1R increases CCND1 and AXIN expression (24).

\section{INSULIN}

Mice that express a dominant negative IGF1R in skeletal muscle (MRK mice) are insulin resistant and exhibit hyperinsulinemia (25). MRK mice are not obese and they have mild hyperglycemia (25). Mouse breast cancer cells that express oncogenes form tumors when grafted into the mammary fat pad of mice. The growth of such tumors is increased in MRK mice compared with wild type mice (26). High levels of insulin activate the insulin receptor (IR), but not the IGF1R, in tumors in MRK mice (27). Mice treated with the insulin analog AspB10 develop larger mammary tumors than vehicle-dosed mice (27). The IR, but not the IGF1R, is activated in tumors in mice treated with AspB10 (27). Western blot analysis reveals that MRK mammary tumors exhibit higher levels of phosphorylated AKT and S6 ribosomal protein (S6rp) than mammary tumors in control mice (28). MRK mice dosed with pan-class I PI3K inhibitor NVP-BKM120 or the dual PI3K/mTOR inhibitor BEZ235 had smaller tumors than MRK mice treated with vehicle (28). PPP inhibits tumor growth in MRK mice without inducing significant metabolic toxicity (29). This PPP benefit was attributed to partial inhibition of the IGF1R and IR, as discussed by the authors (29).

\section{TCDD AND THE ARYL HYDROCARBON RECEPTOR IMPACT IGF2 SIGNALING IN BREAST CANCER CELLS}

Obesity increases the risk for several cancers including breast cancer (30). We (and others) have shown that adipocyte conditioned medium (adipo-CM) stimulates the proliferation of human breast cancer cells more than fibroblast conditioned medium (fibro-CM) $(31,32)$. We identified that adipocytes secrete higher levels of IGF2 than fibroblasts (32). Adipo-CM-stimulated breast cancer cell proliferation was inhibited with anti-IGF2 blocking antibody (32). 2,3,7,8 tetrachlorodibenzo-p-dioxin (TCDD) is a lipophilic toxicant that inhibits estrogen signaling and disrupts interactions between CCND1, CDK4, and RB1 $(33,34)$. We found that TCDD inhibits adipo-CM- or IGF2-stimulated breast cancer cell proliferation and reduces the expression of E2F1, CCND1, MYB, SRC, $J A K 2$, and JUND1 compared with vehicle (32). Taken together, these data suggest that TCDD inhibits adipo-CM and IGF2 signaling in breast cancer cells by downregulating the expression of genes that are important for sustaining high rates of proliferation (32). We are currently investigating signaling mechanisms by which TCDD regulates gene expression in human breast cancer cells stimulated with adipokines or IGF2.

The aryl hydrocarbon receptor $(A H R)$ is a ligand-activated transcription factor that is best known for mediating the toxic effects of TCDD (35). Our recent findings indicate that AHR responds to and mediates IGF2 signaling in MCF7 breast cancer cells (36). We found that IGF2-treated MCF7 cells have higher levels of AHR mRNA and protein than control cells (36). We noted that increases in AHR protein correlated with increases in CCND1 expression in cells treated with IGF2 (36). Chromatin immunoprecipitation (ChIP) experiments revealed that the binding of AHR to the CCND1 gene promoter was increased in IGF2-stimulated MCF7 cells compared with vehicle-treated controls (36). We then knocked down AHR with specific interfering RNA and found that reducing AHR levels inhibited IGF2-stimulated increases in CCND1 mRNA and protein in MCF7 cells (36). Considering that CCND1 promotes cell cycle, we asked whether knockdown of AHR inhibits IGF2-stimulated MCF7 proliferation (36). AHR knockdown MCF7 cells are indeed less responsive to IGF2-mediated increases in proliferation than controls (36). Collectively, these findings indicate that IGF2 induces signaling in MCF7 cells that promotes the association of the AHR with the CCND1 gene promoter, which in turn increases proliferation (36).

\section{TUMOR RESISTANCE MECHANISIMS TO IGF1R BLOCKING THERAPY}

Considering the roles of IGF/IGF1R in transformation, tumor growth, and resistance to cell death, anti-IGF1R antibodies were designed for cancer therapy $(17,18)$. Problems associated with the anti-IGF1R antibodies included adverse endocrine effects and limited effectiveness $(17,18)$. The limited effectiveness of anti-IGF1R antibodies has been attributed to tumor resistance $(17,18)$. Recent work has established that IGF1R blocking antibodies have biasedagonism activity toward the IGF1R (37). Further, blockade of the IGF1R with antibody can promote IGF1 signaling through the integrin $\beta 3$ receptor in tumor cells (38). Biased agonism and the binding of IGF1 to the integrin $\beta 3$ receptor are novel mechanisms of tumor resistance to anti-IGF1R antibodies that we will discuss below.

\section{ANTI-IGF1R ANTIBODIES ARE BIASED AGONISTS}

IGF1 is a balanced IGF1R agonist that induces beta arrestin 1 ( $\beta$ arr1) and IGF1R kinase signaling pathways $(39,40)$ (Figure 1A). The anti-IGF1R antibody figitumumab (CP) is a biased IGF1R agonist because it suppresses IGF1R kinase activity, but activates $\beta$-arr1 signaling (37) (Figure 1B). Increases in $\beta$-arr1 signaling in response to $\mathrm{CP}$ will mediate mitogenic ERK signaling and proteasome-mediated downregulation of the IGF1R (37) (Figure 1B). Combining the ERK inhibitor UO126 with CP reduces the proliferation of Ewing's sarcoma (ES) cells more than UO126 or CP alone (37). Thus, the results of Zheng et al. (37) indicate that blockade of ERK by ERK inhibitors may improve the clinical benefits of CP and other anti-IGF1R antibodies that are biased $\beta$-arr1 agonists (37).

\section{IGF1 BINDS TO INTEGRIN $\beta 3$}

Shin and colleagues in 2013 tested the effectiveness of the antiIGF1R antibody cixutumumab (cix) on a panel of human head and neck squamous cell carcinoma (HNSCC) and non-small cell lung cancer (NSCLC) cell lines (38). The authors found that the growth of some, but not all, tested cancer cell lines was inhibited by cix (38). Western blot analysis showed that the levels of phosphorylated Src, epidermal growth factor receptor (EGFR), AKT, mTOR, and p70S6K were higher in cix-treated resistant cancer cells than cix-sensitive cells (38). The authors recognized that IGF1 had previously been shown to bind to and activate integrin $\beta 3$, but not integrin $\beta 1$, on Chinese hamster ovary cells (41). Binding assays established that IGF1 also binds to integrin $\beta 3$ on HNSCC cells (38). Inhibiting the binding of IGF1 to the integrin $\beta 3$ receptor in cix-treated HNSCC cells blocked increases in Src signaling (38). 


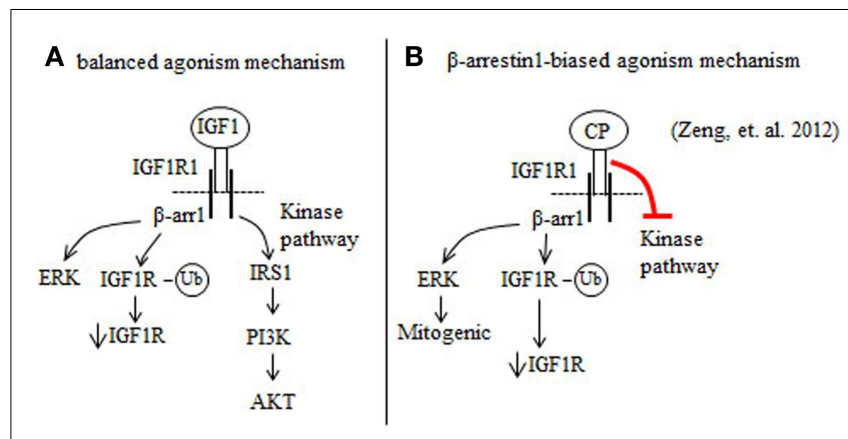

FIGURE 1 | Figitumumab (CP) is a biased agonist of the IGF1R that selectively promotes $\beta$-arrestin 1 ( $\beta$-arr1) signaling in cancer cells. (A) IGF1 binding to and activation of the IGF1R stimulates the $\beta$-arr1 pathway that leads to proteasomal degradation of the IGF1R through a ubiquitin (Ub)-mediated mechanism and ERK activation. IGF1 binding to the IGF1R also induces IGF1R autophosphorylation and this serves to increase the kinase pathway that promotes the phosphorylation and activation of AKT. (B) CP binding to the IGF1R preferentially increases $\beta$-arr1 signaling, and inhibits the IGF1R kinase pathway. By this mechanism, CP downregulates IGF1R and AKT signaling, and increases ERK-mediated mitogenic signaling.

Next, the authors transplanted HNSCC tumors from patients into mice (38). Such tumors were not growth inhibited in mice dosed with cix compared to controls (38). Knockdown of integrin $\beta 3$ or inhibiting Src in primary human HNSCC rendered the tumor xenografts sensitive to cix treatment in mice (38). Collectively, these findings indicate that blockade of the IGF1R with cix induces IGF1 to bind to integrin $\beta 3$, which in turn induces Src signaling that increases cancer cell growth (38).

\section{NEW BLOCKING STRATEGIES}

MEDI-573 is a human antibody that selectively targets IGF1 and IGF2, but not insulin (42) (Figure 2). MEDI-573 affinity for human IGF2 is higher than its affinity for human IGF1 and its affinity for murine IGF1 is low (42). IGF2 binding to the insulin receptor isoform $\mathrm{A}$ (IR-A) in cancer cells has mitogenic and tumor promoting effects in vitro and in vivo $(43,44)$ (Figure 2). Because MEDI-573 targets IGF2, it could be particularly effective in tumors that overexpress IR-A (42). Combining an anti-IGF1R antibody with MEDI-573 offers a better antitumor effect because of greater inhibition of IGF1 and IGF2 signaling in cancer cells and tumor angiogenesis is inhibited (45) (Figure 2). In addition, MEDI-573 combined with an mTOR1 inhibitor (AZD2014) inhibits sarcoma xenografts more than MEDI-573 or mTOR1 inhibition alone (46). MEDI-573 has been tested in phase I clinical trials in solid tumors $(47,48)$. These trials showed that MEDI-573 effectively clears IGF1 and IGF2 from plasma in patients at doses below limiting toxicity $(47,48)$. The most frequent adverse effects of MEDI-573 were fatigue and gastrointestinal complaints $(47,48)$. Immunogenicity against MEDI-573 was evaluated and none was found $(47,48)$. Clinically, the tumor response to MEDI-573 was stable disease (in $\sim 30 \%$ of patients) and no partial or complete responses occurred $(47,48)$.

OSI-906 is a small molecule IGF1R/IR kinase inhibitor that suppresses the growth of tumor xenografts in mice (49) (Figure 2).

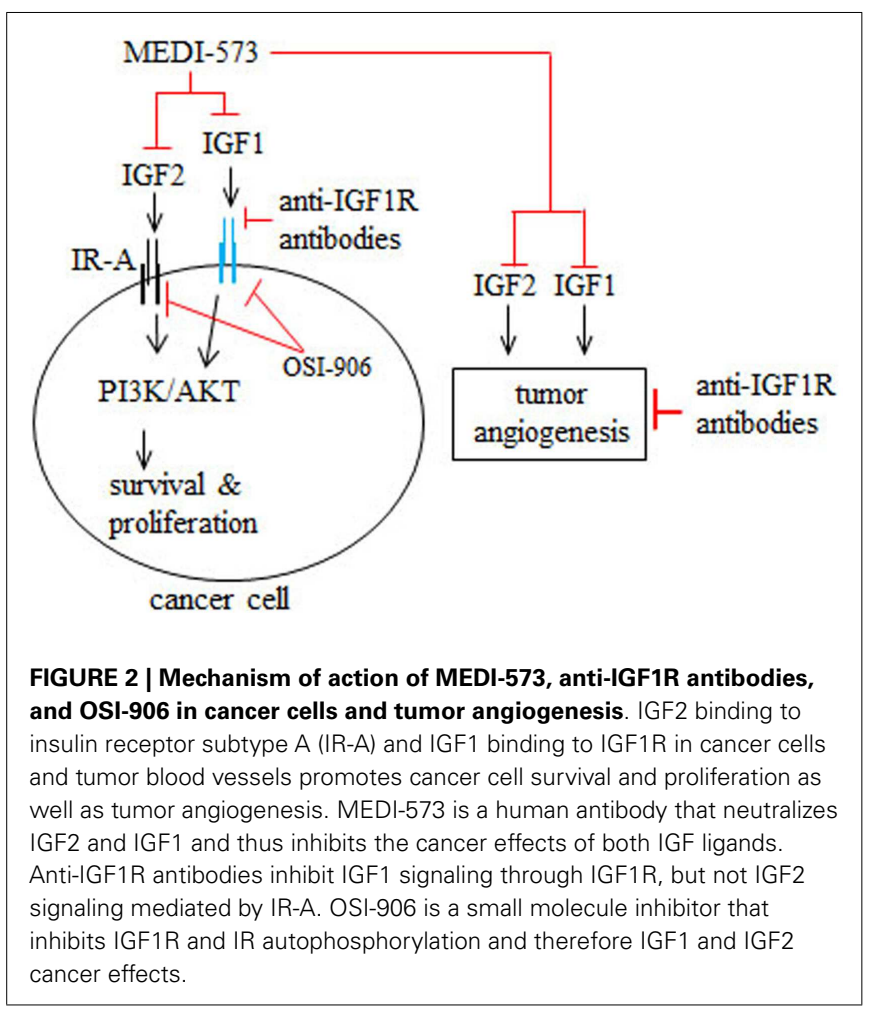

Phase I trials have tested intermittent versus continual dosing of OSI-906 in patients with advanced solid tumors $(50,51)$. In both OSI-906 trials, hyperglycemia was an adverse effect, which occurred more frequently in a diabetic cohort in the continual dosing study (51). Stable disease occurred in patients dosed intermittently or continually with OSI-906 (50, 51). Further, two patients with adrenocortical carcinoma had partial responses to intermittent doses of OSI-906 (50). In the continuous dose study, one patient with melanoma had a complete response to OSI-906 (51). Overall, OSI-906 was well tolerated has antitumor activity and warrants further study, as discussed by the authors $(50,51)$.

\section{CONCLUSION}

From all apparent evidences, we propose that the insulin/IGF system is still an effective target for cancer therapy. There is still a need for uncovering new ways to effectively target both insulin and IGF signaling in cancer while avoiding significant metabolic toxicity. Part will come from the recognition of new pathways of tumor resistance. There is also a need to identify specific biomarkers to predict sensitivity or resistance to existing anti-IGF1R therapies (52). Thus, collectively, insulin/IGF signaling in cancer and its therapeutic targeting still warrants further investigation.

\section{REFERENCES}

1. Sell C, Dumenil G, Deveaud C, Miura M, Coppola D, DeAngelis T, et al. Effect of a null mutation of the insulin-like growth factor I receptor gene on growth and transformation of mouse embryo fibroblasts. Mol Cell Biol (1994) 14:3604-12.

2. Sell C, Rubini M, Rubin R, Liu JP, Efstratiadis A, Baserga R. Simian virus 40 large tumor antigen is unable to transform mouse embryonic fibroblasts lacking type 1 insulin-like growth factor receptor. Proc Natl Acad Sci U S A (1993) 90:11217-21. doi:10.1073/pnas.90.23.11217 
3. Toretsky JA, Kalebic T, Blakesley V, LeRoith D, Helman LJ. The insulin-like growth factor-I receptor is required for EWS/FLI-1 transformation of fibroblasts. J Biol Chem (1997) 272:30822-7. doi:10.1074/jbc.272.49.30822

4. Valentinis B, Morrione A, Taylor SJ, Baserga R. Insulin-like growth factor I receptor signaling in transformation by src oncogenes. Mol Cell Biol (1997) 17:3744-54

5. Liu JL, Blakesley VA, Gutkind JS, LeRoith D. The constitutively active mutant Galpha13 transforms mouse fibroblast cells deficient in insulin-like growth factor-I receptor. J Biol Chem (1997) 272:29438-41. doi:10.1074/jbc.272.47. 29438

6. Klinakis A, Szabolcs M, Chen G, Xuan S, Hibshoosh H, Efstratiadis A. Igflr as a therapeutic target in a mouse model of basal-like breast cancer. Proc Natl Acad Sci U S A (2009) 106:2359-64. doi:10.1073/pnas.0810221106

7. Wu Y, Yakar S, Zhao L, Hennighausen L, LeRoith D. Circulating insulin-like growth factor-I levels regulate colon cancer growth and metastasis. Cancer Res (2002) 62:1030-5.

8. Yakar S, Liu JL, Stannard B, Butler A, Accili D, Sauer B, et al. Normal growth and development in the absence of hepatic insulin-like growth factor I. Proc Natl Acad Sci U S A (1999) 96:7324-9. doi:10.1073/pnas.96.13.7324

9. Wu Y, Cui K, Miyoshi K, Hennighausen L, Green JE, Setser J, et al. Reduced circulating insulin-like growth factor I levels delay the onset of chemically and genetically induced mammary tumors. Cancer Res (2003) 63:4384-8.

10. DiGiovanni J, Kiguchi K, Frijhoff A, Wilker E, Bol DK, Beltran L, et al. Deregulated expression of insulin-like growth factor 1 in prostate epithelium leads to neoplasia in transgenic mice. Proc Natl Acad Sci U S A (2000) 97:3455-60. doi:10.1073/pnas.97.7.3455

11. Yamamoto M, Fukuoka H, Iguchi G, Matsumoto R, Takahashi M, Nishizawa $\mathrm{H}$, et al. The prevalence and associated factors of colorectal neoplasms in acromegaly: a single center based study. Pituitary (2014). doi:10.1007/s11102014-0580-y

12. Guevara-Aguirre J, Balasubramanian P, Guevara-Aguirre M, Wei M, Madia F, Cheng CW, et al. Growth hormone receptor deficiency is associated with a major reduction in pro-aging signaling, cancer, and diabetes in humans. Sci Transl Med (2011) 3:70ra13. doi:10.1126/scitranslmed.3001845

13. Metz HE, Houghton AM. Insulin receptor substrate regulation of phosphoinositide 3-kinase. Clin Cancer Res (2011) 17:206-11. doi:10.1158/1078-0432.CCR10-0434

14. Siddle K. Signalling by insulin and IGF receptors: supporting acts and new players. J Mol Endocrinol (2011) 47:R1-10. doi:10.1530/JME-11-0022

15. Siddle K. Molecular basis of signaling specificity of insulin and IGF receptors: neglected corners and recent advances. Front Endocrinol (2012) 3:34. doi:10.3389/fendo.2012.00034

16. Taniguchi CM, Emanuelli B, Kahn CR. Critical nodes in signalling pathways: insights into insulin action. Nat Rev Mol Cell Biol (2006) 7:85-96. doi: $10.1038 / \mathrm{nrm} 1837$

17. Pollak M. Insulin and insulin-like growth factor signalling in neoplasia. Nat Rev Cancer (2008) 8:915-28. doi:10.1038/nrc2536

18. Pollak M. The insulin and insulin-like growth factor receptor family in neoplasia: an update. Nat Rev Cancer (2012) 12:159-69. doi:10.1038/nrc3215

19. Sun H, Tu X, Prisco M, Wu A, Casiburi I, Baserga R. Insulin-like growth factor I receptor signaling and nuclear translocation of insulin receptor substrates 1 and 2. Mol Endocrinol (2003) 17:472-86. doi:10.1210/me.2002-0276

20. Tu X, Batta P, Innocent N, Prisco M, Casaburi I, Belletti B, et al. Nuclear translocation of insulin receptor substrate-1 by oncogenes and Igf-I. Effect on ribosomal RNA synthesis. J Biol Chem (2002) 277:44357-65. doi:10.1074/jbc. M208001200

21. Wu A, Chen J, Baserga R. Nuclear insulin receptor substrate-1 activates promoters of cell cycle progression genes. Oncogene (2008) 27:397-403. doi:10.1038/sj. onc. 1210636

22. Drakas R, Tu X, Baserga R. Control of cell size through phosphorylation of upstream binding factor 1 by nuclear phosphatidylinositol 3-kinase. Proc Natl Acad Sci U S A (2004) 101:9272-6. doi:10.1073/pnas.0403328101

23. Sehat B, Tofigh A, Lin Y, Trocme E, Liljedahl U, Lagergren J, et al. SUMOylation mediates the nuclear translocation and signaling of the IGF-1 receptor. Sci Signal (2010) 3:ra10. doi:10.1126/scisignal.2000628

24. Warsito D, Sjostrom S, Andersson S, Larsson O, Sehat B. Nuclear IGF1R is a transcriptional co-activator of LEF1/TCF. EMBO Rep (2012) 13:244-50. doi:10.1038/embor.2011.251
25. Fernandez AM, Kim JK, Yakar S, Dupont J, Hernandez-Sanchez C, Castle AL, et al. Functional inactivation of the IGF-I and insulin receptors in skeletal muscle causes type 2 diabetes. Genes Dev (2001) 15:1926-34. doi:10.1101/gad.908001

26. Novosyadlyy R, Lann DE, Vijayakumar A, Rowzee A, Lazzarino DA, Fierz Y, et al. Insulin-mediated acceleration of breast cancer development and progression in a nonobese model of type 2 diabetes. Cancer Res (2010) 70:741-51. doi:10.1158/0008-5472.CAN-09-2141

27. Gallagher EJ, Alikhani N, Tobin-Hess A, Blank J, Buffin NJ, Zelenko Z, et al. Insulin receptor phosphorylation by endogenous insulin or the insulin analog AspB10 promotes mammary tumor growth independent of the IGF-I receptor. Diabetes (2013) 62:3553-60. doi:10.2337/db13-0249

28. Gallagher EJ, Fierz Y, Vijayakumar A, Haddad N, Yakar S, LeRoith D. Inhibiting PI3K reduces mammary tumor growth and induces hyperglycemia in a mouse model of insulin resistance and hyperinsulinemia. Oncogene (2012) 31:3213-22. doi:10.1038/onc.2011.495

29. Rostoker R, Bitton-Worms K, Caspi A, Shen-Orr Z, LeRoith D. Investigating new therapeutic strategies targeting hyperinsulinemia's mitogenic effects in a female mouse breast cancer model. Endocrinology (2013) 154:1701-10. doi:10.1210/en.2012-2263

30. Calle EE, Kaaks R. Overweight, obesity and cancer: epidemiological evidence and proposed mechanisms. Nat Rev Cancer (2004) 4:579-91. doi:10.1038/ nrc1408

31. Iyengar P, Combs TP, Shah SJ, Gouon-Evans V, Pollard JW, Albanese C, et al. Adipocyte-secreted factors synergistically promote mammary tumorigenesis through induction of anti-apoptotic transcriptional programs and proto-oncogene stabilization. Oncogene (2003) 22:6408-23. doi:10.1038/sj.onc. 1206737

32. Salisbury TB, Morris GZ, Tomblin JK, Chaudhry AR, Cook CR, Santanam N. Aryl hydrocarbon receptor ligands inhibit igf-ii and adipokine stimulated breast cancer cell proliferation. ISRN Endocrinol (2013) 2013:104850. doi:10.1155/2013/104850

33. Barhoover MA, Hall JM, Greenlee WF, Thomas RS. Aryl hydrocarbon receptor regulates cell cycle progression in human breast cancer cells via a functional interaction with cyclin-dependent kinase 4. Mol Pharmacol (2010) 77:195-201. doi:10.1124/mol.109.059675

34. Wormke M, Stoner M, Saville B, Walker K, Abdelrahim M, Burghardt R, et al. The aryl hydrocarbon receptor mediates degradation of estrogen receptor alpha through activation of proteasomes. Mol Cell Biol (2003) 23:1843-55. doi:10.1128/MCB.23.6.1843-1855.2003

35. Denison MS, Soshilov AA, He G, DeGroot DE, Zhao B. Exactly the same but different: promiscuity and diversity in the molecular mechanisms of action of the aryl hydrocarbon (dioxin) receptor. Toxicol Sci (2011) 124:1-22. doi:10.1093/toxsci/kfr218

36. Tomblin JK, Salisbury TB. Insulin like growth factor 2 regulation of aryl hydrocarbon receptor in MCF-7 breast cancer cells. Biochem Biophys Res Commun (2014) 443:1092-6. doi:10.1016/j.bbrc.2013.12.112

37. Zheng H, Shen H, Oprea I, Worrall C, Stefanescu R, Girnita A, et al. Beta-arrestinbiased agonism as the central mechanism of action for insulin-like growth factor 1 receptor-targeting antibodies in Ewing's sarcoma. Proc Natl Acad Sci U S A (2012) 109:20620-5. doi:10.1073/pnas.1216348110

38. Shin DH, Lee HJ, Min HY, Choi SP, Lee MS, Lee JW, et al. Combating resistance to anti-IGFR antibody by targeting the integrin beta3-Src pathway. J Natl Cancer Inst (2013) 105:1558-70. doi:10.1093/jnci/djt263

39. Girnita L, Shenoy SK, Sehat B, Vasilcanu R, Girnita A, Lefkowitz RJ, et al. \{beta\}Arrestin is crucial for ubiquitination and down-regulation of the insulin-like growth factor-1 receptor by acting as adaptor for the MDM2 E3 ligase. J Biol Chem (2005) 280:24412-9. doi:10.1074/jbc.M501129200

40. Girnita L, Shenoy SK, Sehat B, Vasilcanu R, Vasilcanu D, Girnita A, et al. Beta-arrestin and Mdm2 mediate IGF-1 receptor-stimulated ERK activation and cell cycle progression. J Biol Chem (2007) 282:11329-38. doi:10.1074/jbc. M611526200

41. Saegusa J, Yamaji S, Ieguchi K, Wu CY, Lam KS, Liu FT, et al. The direct binding of insulin-like growth factor-1 (IGF-1) to integrin alphavbeta3 is involved in IGF-1 signaling. J Biol Chem (2009) 284:24106-14. doi:10.1074/jbc.M109.013201

42. Gao J, Chesebrough JW, Cartlidge SA, Ricketts SA, Incognito L, Veldman-Jones $\mathrm{M}$, et al. Dual IGF-I/II-neutralizing antibody MEDI-573 potently inhibits IGF signaling and tumor growth. Cancer Res (2011) 71:1029-40. doi:10.1158/00085472.CAN-10-2274 
43. Frasca F, Pandini G, Scalia P, Sciacca L, Mineo R, Costantino A, et al. Insulin receptor isoform A, a newly recognized, high-affinity insulin-like growth factor II receptor in fetal and cancer cells. Mol Cell Biol (1999) 19:3278-88.

44. Ulanet DB, Ludwig DL, Kahn CR, Hanahan D. Insulin receptor functionally enhances multistage tumor progression and conveys intrinsic resistance to IGF-1R targeted therapy. Proc Natl Acad Sci U S A (2010) 107:10791-8. doi:10.1073/pnas.0914076107

45. Bid HK, London CA, Gao J, Zhong H, Hollingsworth RE, Fernandez S, et al. Dual targeting of the type 1 insulin-like growth factor receptor and its ligands as an effective antiangiogenic strategy. Clin Cancer Res (2013) 19:2984-94. doi:10.1158/1078-0432.CCR-12-2008

46. Zhong H, Fazenbaker C, Breen S, Chen C, Huang J, Morehouse C, et al. MEDI573 , alone or in combination with mammalian target of rapamycin inhibitors, targets the insulin-like growth factor pathway in sarcomas. Mol Cancer Ther (2014) 13:2662-73. doi:10.1158/1535-7163.MCT-14-0144

47. Haluska P, Menefee M, Plimack ER, Rosenberg J, Northfelt D, LaVallee T, et al. Phase I dose-escalation study of MEDI-573, a bispecific, antiligand monoclonal antibody against IGFI and IGFII, in patients with advanced solid tumors. Clin Cancer Res (2014) 20:4747-57. doi:10.1158/1078-0432.CCR-14-0114

48. Iguchi H, Nishina T, Nogami N, Kozuki T, Yamagiwa Y, Yagawa K. Phase I doseescalation study evaluating safety, tolerability and pharmacokinetics of MEDI573, a dual IGF-I/II neutralizing antibody, in Japanese patients with advanced solid tumours. Invest New Drugs (2014) 33:194-200. doi:10.1007/s10637-0140170-x

49. Mulvihill MJ, Cooke A, Rosenfeld-Franklin M, Buck E, Foreman K, Landfair D, et al. Discovery of OSI-906: a selective and orally efficacious dual inhibitor of the IGF-1 receptor and insulin receptor. Future Med Chem (2009) 1:1153-71. doi: $10.4155 /$ fmc.09.89
50. Jones RL, Kim ES, Nava-Parada P, Alam S, Johnson FM, Stephens AW, et al. Phase I study of intermittent oral dosing of the insulin-like growth factor-1 and insulin receptors inhibitor OSI-906 in patients with advanced solid tumors. Clin Cancer Res (2014) 21:1-8. doi:10.1158/1078-0432.CCR-14-0265

51. Puzanov I, Lindsay CR, Goff LW, Sosman JA, Gilbert J, Berlin J, et al. A phase I study of continuous oral dosing of OSI-906, a dual inhibitor of insulin-like growth factor- 1 and insulin receptors in patients with advanced solid tumors. Clin Cancer Res (2014). doi:10.1158/1078-0432.CCR-14-0303

52. King H, Aleksic T, Haluska P, Macaulay VM. Can we unlock the potential of IGF-1R inhibition in cancer therapy? Cancer Treat Rev (2014) 40:1096-105. doi:10.1016/j.ctrv.2014.07.004

Conflict of Interest Statement: The authors declare that the research was conducted in the absence of any commercial or financial relationships that could be construed as a potential conflict of interest.

Received: 11 December 2014; paper pending published: 06 January 2015; accepted: 19 January 2015; published online: 02 February 2015.

Citation: Salisbury TB and Tomblin JK (2015) Insulin/insulin-like growth factors in cancer: new roles for the aryl hydrocarbon receptor, tumor resistance mechanisms, and new blocking strategies. Front. Endocrinol. 6:12. doi: 10.3389/fendo.2015.00012

This article was submitted to Cancer Endocrinology, a section of the journal Frontiers in Endocrinology.

Copyright (C) 2015 Salisbury and Tomblin. This is an open-access article distributed under the terms of the Creative Commons Attribution License (CC BY). The use, distribution or reproduction in other forums is permitted, provided the original author(s) or licensor are credited and that the original publication in this journal is cited, in accordance with accepted academic practice. No use, distribution or reproduction is permitted which does not comply with these terms. 